$\begin{array}{ccc}\text { Gazi Üniversitesi } & \text { Fen Bilimleri Dergisi } \\ \text { PART C: TASARIM VE TEKNOLOJI } & \text { dergipark.gov.tr/http-gujsc-gazi-edu-tr }\end{array}$

\title{
Seri ve Paralel Bağlı Karşıt Akışlı Ranque-Hilsch Vorteks Tüpün Isıtma- Soğutma Performansının Karşılaştırılması
}

\author{
*Volkan KIRMACI \\ "Bartın Üniversitesi, Mühendislik Fakültesi, Makina Mühendisliği Bölümü, 74100, BARTIN
}

\begin{abstract}
$\ddot{O} \mathbf{z}$
Makale Bilgisi

Başvuru: 01/08/201X

Düzeltme: 07/09/201X

Kabul: 07/09/201X

Anahtar Kelimeler

Ranque-Hilsch vorteks tüp

Bu çalıșmada, sıcak akıșkan çıkıș tarafındaki kontrol vanası hariç hareketli parçası olmayan gövde uzunluğu $100 \mathrm{~mm}$, iç çapı $7 \mathrm{~mm}$ olan iki adet karşıt akışlı Ranque-Hilsch Vorteks Tüp (RHVT) birbirine seri ve paralel olarak birbirine bağlanmıștır. Birbirine seri ve paralel bağlanan RHVT'de Polyamid Plastik, Alüminyum ve Pirinç malzemeden üretilmiş altı orfisli nozul kullanılmıștır. Birbirine seri ve paralel bağlanan RHVT'de giriș basınc1 $200 \mathrm{kPa}$ ' dan $600 \mathrm{kPa}$ basınç değerine kadar $50 \mathrm{kPa}$ aralıklarla basınçlı hava kullanılarak 1sıtma-soğutma sıcaklık performansları deneysel olarak karşılaştırılmıştır. Deneysel sonuçlar değerlendirildiğinde, en düşük soğuk akışkan sıcaklığı $600 \mathrm{kPa}$ giriş basınç değerinde Alüminyumun malzemeden üretilmiş nozulda $-19.6{ }^{\circ} \mathrm{C}$ paralel bağlı deneysel sistemde olduğu, en yüksek sıcak akışkan sıcaklığı ise $600 \mathrm{kPa}$ giriș basınç değerinde Pirinç malzemeden üretilmiş nozulda $41.6{ }^{\circ} \mathrm{C}$ Paralel bağlı deneysel sistemde olduğu tespit edilmiştir.
\end{abstract} Soğutma

Ekserji Analizi

Keywords

Ranque-Hilsch vortex tube Cooling

Exergy analysis

\section{The Comparision of Heating and Cooling Performance of a Serial and Parallel Connected Counter Flow Ranque-Hilsch Vortex Tube}

\begin{abstract}
In this study, two counter flow Ranque-Hilsch Vortex Tubes with body length $100 \mathrm{~mm}$ and inlet diameter $7 \mathrm{~mm}$ were used having no moving parts except a control valve for adjustment of volume flow rates. Six-orifice nozzles were used which are made of polyamid plastic, aluminum and brass in the two vortex tubes connected with each other serial and parallel. Heating and cooling performance of vortex tubes were compared experimentally by using compressed air as a working fluid in RHVT with pressure values from $200 \mathrm{kPa}$ to $600 \mathrm{kPa}$ with $50 \mathrm{kPa}$ variation. Minimum cold fluid and maximum hot fluid temperatures were both determined for parallel connection setup. The minimum cold fluid temperature was obtained at $600 \mathrm{kPa}$ inlet pressure with aluminum nozzle material as $-19.6{ }^{\circ} \mathrm{C}$ while the maximum hot fluid temperature was obtained at $600 \mathrm{kPa}$ inlet pressure with brass material as $41.6{ }^{\circ} \mathrm{C}$.
\end{abstract}

\section{GİRISș}

Vorteks tüpler George Joseph Ranque tarafindan 1931 yılında keşfedilmiş ve 1947 y1lında Rudoph Hilsch tarafından geliştirilmiştir. Vorteks tüpler iki araştırmacıların isimleri ile Ranque-Hilsch Vorteks Tüpü (RHVT) olarak isimlendirilmiştir [1,2]. RHVT, kontrol vanası hariç hareketli parçası olmayan bir boru sistemdir. RHVT basınçlı akışkan ile çalışarak, hem ısıtma hem de soğutma işlemi aynı anda meydana gelmektedir [3, 4]. Boyutlarının ufak ve ağırlığının hafif olması, rejime hızlı girmesi, herhangi bir kimyasal akışkana ihtiyaç olmamasından çevresel açıdan zararlı olmamalarından dolayı RHVT'ler birçok 1sıtma ve soğutma proseslerine çözüm olabilmektedirler [5]. Karşıt ve paralel akışlı olmak RHVT’ler akış özelliklerine göre ikiye ayrılmalarına rağmen, tüm RHVT'ler çalışma prensipleri aynıdır [6]. Şekil 1 de bu çalışmada kullanılan karşıt akışı 


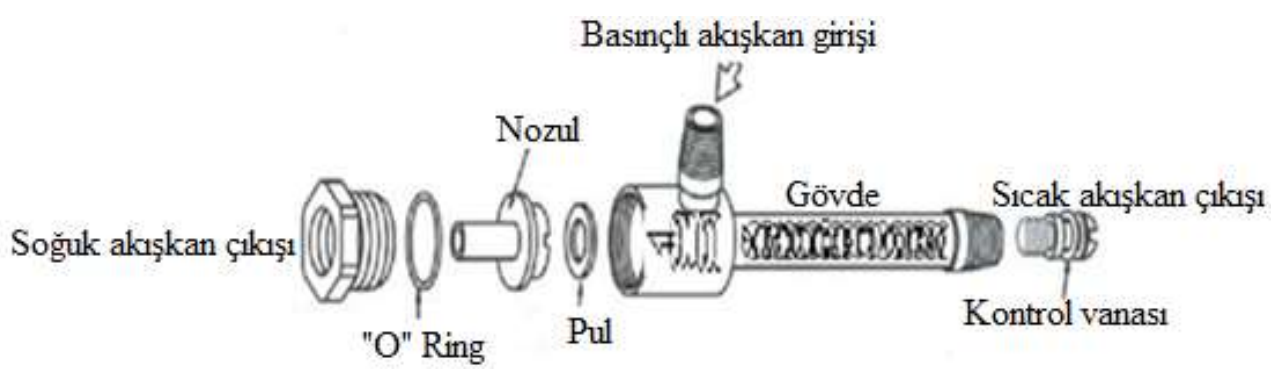

Şekil 1. Deneysel sistemde kullanılan karşıt akışlı RHVT yapısı

Şekil 2 ve Şekil 3'de RHVT'ler ile aynı anda sıcak ve soğuk akış elde edilmesi, iki farklı açısal hızlarda dönen akış arasında oluşan mekanik enerji transferi gösterilmiştir. RHVT'ne basınçlı akışkan, giriş ağzında bulunan nozuldan geçerek girmektedir. Tüp girişindeki nozul ile basınçlı olan giriş akışkanının basıncını azaltarak hızın artmasını sağlamaktır. Nozuldan geçen akışkan, tüpe giren basınçlı akışkana bağımlı olarak tüpün silindirik şeklinden dolayı çok yüksek açısal hızlarda dönmeye başlamaktadır. Bu esnasında, akış merkezkaç kuvvetin etkisi ile tüp cidarına doğru genişlemeye başlamaktadır. Bunun sonucunda da tüp merkezindeki akışkan ile tüp cidarındaki akışkan arasında basınç farkı oluşmaktadır. Oluşan basınç farkı sonucu ile akış radyal yönde merkeze doğru genişlemektedir. Merkezdeki akışın açısal hızı, açısal momentumun korunumu ilkesinden dolayı tüp cidarındaki akışının açısal hızından daha yüksek değerdedir. Bunun sonucu tüp içerisinde iki farklı hızlarda dönen iki akışkan oluşmaktadır. Merkezdeki akışkan daha yüksek hıza sahip olduğundan dolayı yüzeydeki akışkanı hızlanarak merkezdeki akıştan cidardaki akışkana mekanik enerji transferi oluşmaktadır. Mekanik enerjisi azalan merkezdeki akışkan soğuk akışı, tüp cidardaki sürtünme etkisi ve merkezdeki akışkandan aldığı mekanik enerjiden dolayı tüp cidarındaki akış sıcak akıştır. Şekil 1'de gösterildiği gibi, Karşıt akışlı RHVT soğuk akış, sıcak akışın çıktığı uçta bulunan kontrol vanasından dolayı bir durgunluk noktasından sonra akışkan geriye doğru dönmektedir. Bunun sonucunda, RHVT'lerde aynı anda bir tarafından soğuk akış, diğer tarafından da sıcak akış elde edilmektedir. [1, 7-11].

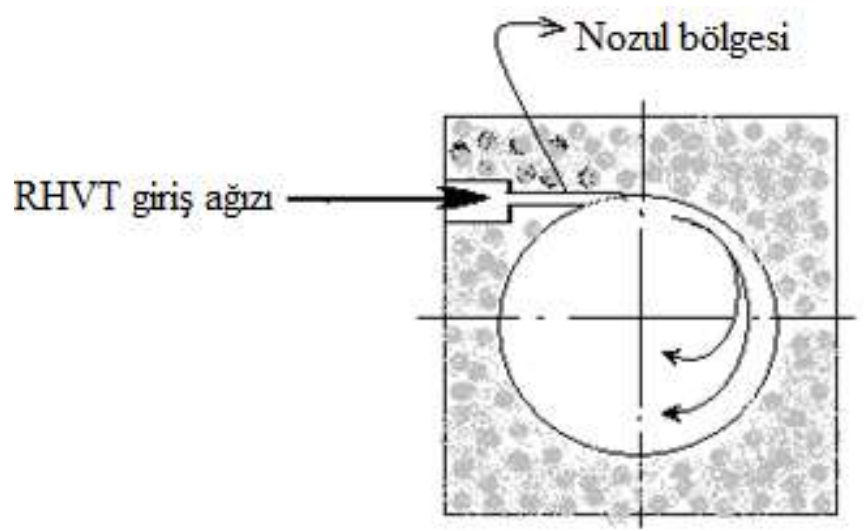

Şekil 2. Akışın RHVT teğetsel olarak nozuldan gönderilmesi 


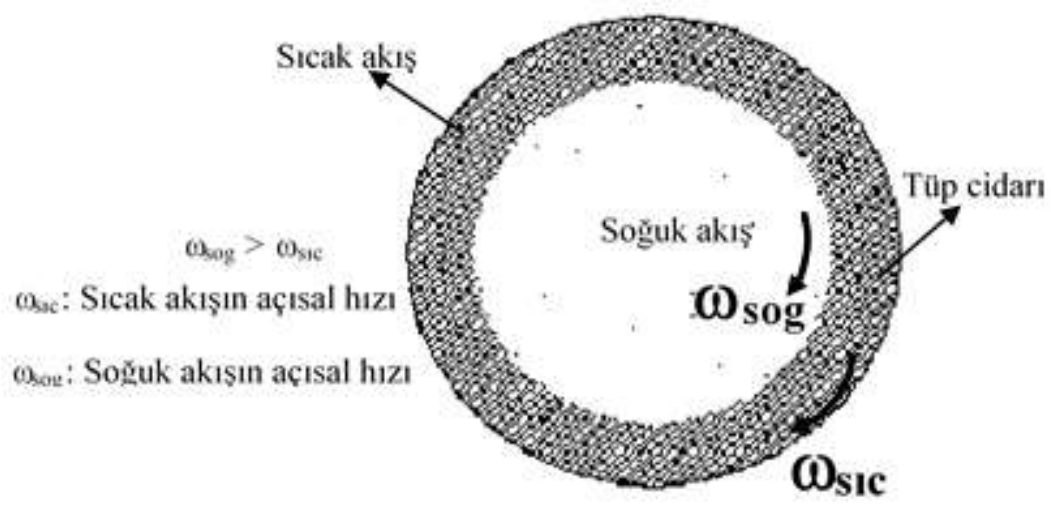

Şekil 3. RHVT içindeki slcak ve soğuk aklşın hareketi

Usta vd., vorteks tüpünde oluşan enerji ayrışma olayını iki farklı akışkan ile yaptıkları deneysel çalışmada incelemişlerdir. Yapılan deneysel çalışma sonucunda, hava ve karbondioksit gazına ait grafikler oluşturmuşlardır. Havanın performansının karbondioksite göre daha yüksek olduğunu göstermişlerdir [11]. Kırmacı yaptığı çalışmada, vorteks tüpünde basınçlı akışkan olarak hava kullanmıştır. Vorteks giriş basıncı $150 \mathrm{kPa}$ 'dan başlayarak $700 \mathrm{kPa}$ 'a kadar $50 \mathrm{kPa}$ aralıklarla uygulamıştır. Vorteks tüpünde, soğuk akışkanın hacimsel debisinin girişteki akışkanın hacimsel debisine oranı $\mathrm{y}_{\mathrm{c}}$, olarak tanımlamış ve $\mathrm{y}_{\mathrm{c}} 0.5$ oranından başlayarak 0.02 aralıklarla 0.70 ' e kadar değiştirerek tüm basınç değerlerine göre sistem performansını deneysel olarak incelemiştir. Çalışma sonucunda sıcak akışkan sıcaklığı, $\mathrm{y}_{\mathrm{c}}$ oranı 0.50 ile 0.70 arasında vorteks tüpüne giriş basıncı artıkça, vorteks tüpünden çıkan sıcak akışkan sıcaklığının arttığını belirtmiştir [12]. Kırmacı ve Uluer yaptıkları deneysel çalışmada, orifis nozul sayısının ve karşıt akışlı RHVT giriş basıncının, karşıt akışlı RHVT 1sıtma ve soğutma performanslarına olan etkisini deneysel incelemişlerdir. Deneylerin sonucunda, sıcak ve soğuk çıkışlar arasındaki sıcaklık farkının; artan giriş basıncıyla arttığı, artan nozul sayısıyla azaldığını tespit etmişlerdir [13]. Kırmacı yaptığı deneysel çalışmada, Ranque-Hilsch vorteks tüpünde akışkan olarak hava ve oksijen kullanılarak farklı giriş basıncı ve farklı nozullarda sitemin 1sıtma, soğutma performansını incelemiş ve enerji analizlerini yapmıştır [14]. Markal yaptı̆̆ yüksek lisans tez çalışmasında, deneysel olarak vorteks tüpünde kullanılan nozul geometrisi tasarımı, vorteks tüp gövde uzunluğunu, giriş basıncına göre ve tapa uç açısının sistem performansına olan etkisini incelemiştir. Bu inceleme sonucunda nem etkisinin, yalıtımın ve ortam sıcaklığının vorteks tüp performansına etkisini gözlemlemiş ve durma noktasının yerini tespit edebilmek için termal kamera kullanarak; vorteks tüp yüzeyinin sıcaklık dağılımını belirlemiştir [15]. Cebeci yaptığı yüksek lisans tez çalışmasında, gövde uzunluğu $100 \mathrm{~mm}$, iç çapı $10 \mathrm{~mm}$ olan karşıı akışlı bir RHVT de 2, 3, 4, 5, 6 nozul sayılarında, basınçlı akışkan olarak hava ve oksijen kullanarak $50 \mathrm{kPa}$ aralıklarla, $150 \mathrm{kPa}$ ' dan $700 \mathrm{kPa}$ basınç değerine kadar soğutma ve isıtma performanslarını deneysel olarak incelemiştir. Sistemdeki kayıp iş ve verimi ekserji analizi ile hesaplamıştır [16]. Yüksel yaptığı yüksek lisans tez çalışmasında, talaşlı imalatta kullanılan soğutma sıvılarının insan sağlığına ve çevreye verdiği zararlı etkiler nedeniyle RHVT nin soğutma işlemi talaşlı imalatta incelemiştir. Ayrıca, RHVT nin performansını buhar sıkıştırmalı soğutma sistemine göre düşük olmasına rağmen maliyetin düşük olması ve çabuk rejime girmesi diğer uygulamalara göre RHVT'nin kullanımını ön plana çıkarmıştır [17].

Bu çalışmada, gövde uzunluğu $100 \mathrm{~mm}$, iç çap 7 mm ölçülerinde iki adet karşıt akışlı RHVT'ler birbirine seri ve paralel olarak bağlanarak iki adet deney sistemi oluşturularak, giriş basınc1 $200 \mathrm{kPa}$ ' dan $600 \mathrm{kPa}$ basınç değerine kadar $50 \mathrm{kPa}$ aralıklarla basınçlı hava kullanılarak soğutma-1sıtma performansları deneysel olarak etkileşimini incelenmiştir. Çalışmamızda kullanılan RHVT'ler Polyamid Plastik, Alüminyum ve Pirinç malzemeden üretilmiş altı orfisli nozul kullanılmıştır. Bu çalışmanın literatürdeki çalışmalarda farkı olarak iki adet karşıt akışlı RHVT'ler birbirine seri ve paralel olarak bağlanarak soğutma-1sıtma performansları deneysel olarak karşılaştııılmıştır. Bu kapsamda, en iyi performansı sağlayan sistemin belirlenmesi amaçlanmıştır. 


\section{MATERYAL VE METOT}

Çalışmada, gövde uzunluğu $10 \mathrm{~mm}$, iç çapı $7 \mathrm{~mm}$, olan iki adet karşıt akışlı RHVT kullanılmıştır. RHVT genişliği $700 \mathrm{~mm}$, boyu $400 \mathrm{~mm}$ ve $1.5 \mathrm{~mm}$ kalınlığındaki sac levha üzerine yatay konumda Şekil 4' de ki gibi seri ve paralel bağlı olarak sabitlenmiştir. Şekil 5'de deneysel sistemde kullanılan Polyamid Plastik, Alüminyum ve Pirinç malzemelerinden üretilmiş nozullar verilmiştir. RHVT giren havanın basıncını ölçmek için \%5 hassasiyetinde PAKKENS marka gliserinli manometre, hacimsel debilerini ölçmek için \%3 hassasiyetinde Trust Science Innovatıon marka debimetreler RHVT çıkışlarına bağlanmıştır. Ayrıca kullanılan debimetre ile bağlandığı noktadaki basınç ve hacimsel debi değerleri okunmaktadır. RHVT çıkan soğuk ve sıcak akış sıcaklıklarını ölçmek için $\pm 1{ }^{\circ} \mathrm{C}$ hassasiyetindeki dijital termometreler kullanılmıştır. Dijital termometrelerin probları RHVT sıcak ve soğuk çıkış taraflarından $0.5 \mathrm{~cm}$ ilerisine $1 \mathrm{~mm}$ çapında delinmiş tüpün merkezine gelecek şekilde yerleştirilmiştir. Sistemde basınçlı akışkan kaynağı olarak kompresör kullanılmıştır. Sistem elemanları arasındaki bağlantılar basınca dayanıklı ve sızdırmazlığa sağlayan pnömatik hortum ile bağlanmıştır. RHVT'nün girişi ile hava kompresörü arasında, 10 bar basınç dayanımı olan pnömatik hortum, quick kuplin ile yapılmıştır. Hava kompresörü çalıştırılmış ve deneylerin başlangıç basıncı olan $200 \mathrm{kPa}$ 'lık basınç sağlanmıştır. RHVT çıkan sıcak ve soğuk akışkan çıkışında bulunan ölçüm cihazlarında okunan sıcaklıklar sabit oluncaya kadar $200 \mathrm{kPa}$ basınçlı hava, kompresörden gönderilerek deney tamamlanmıştır. Daha sonra sırasıyla 250, 300, 350, 400, 450, 500, 550 ve $600 \mathrm{kPa}$ basınç değerlerinde polyamid ve alüminyumun malzemesinden imal edilmiş olan nozullarda deneyler yapılmıştır. Tüm deneyler $21{ }^{\circ} \mathrm{C}^{\prime}$ lik ortam sıcaklığında yapılmıştır. Deneyde elde edilen sonuçların doğruluğu için bir deney 3 kez tekrarlanmış ve elde edilen değerlerin ortalamaları alınmıştır.

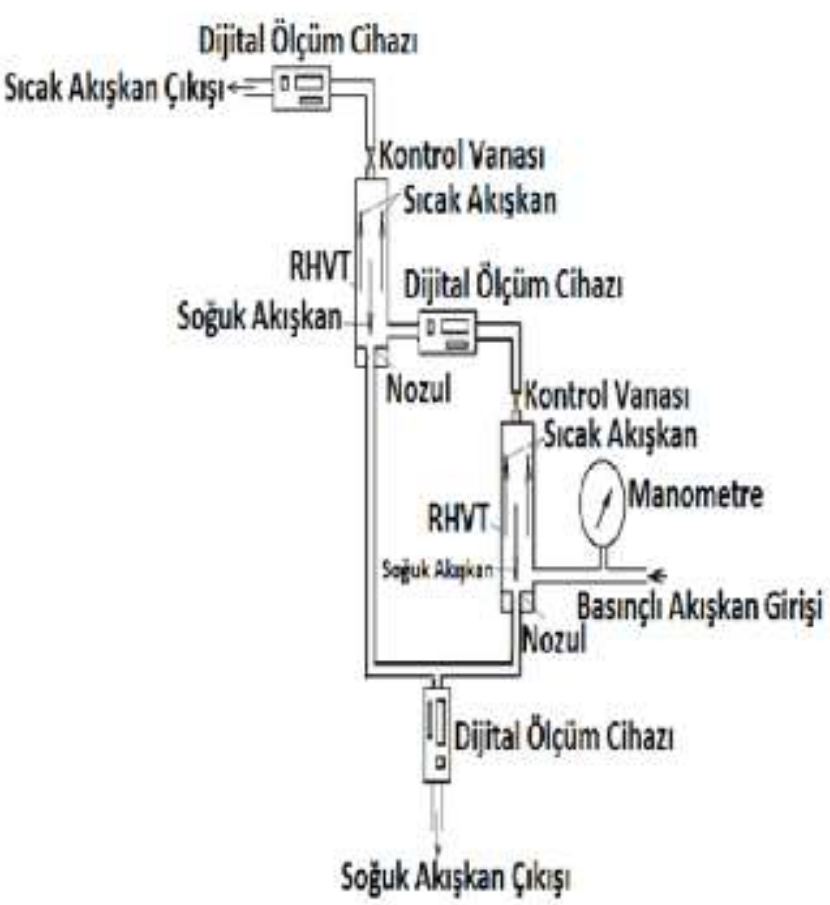

a. Seri bağlı RHVT

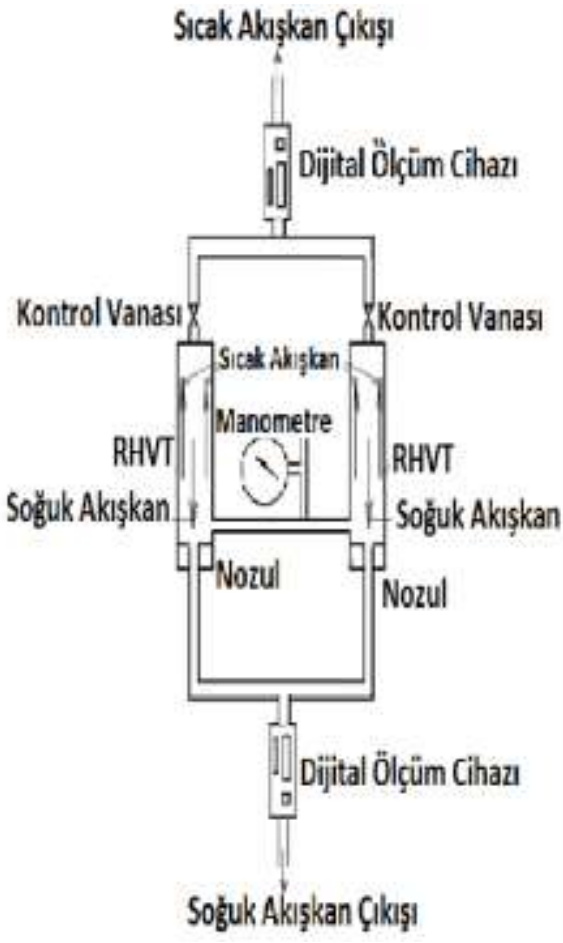

b. Paralel bağlı RHVT

Şekil 4. Deneysel sistem 


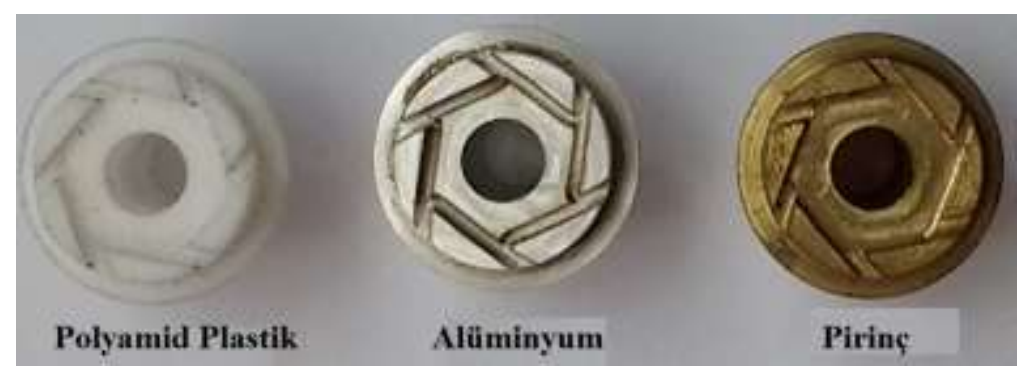

Şekil 5. Deneylerde kullanilan altı orfisli nozullar

\section{BULGULAR VE TARTIŞMA}

Bir giriş ve bir çıkışlı sürekli akışlı açık sistemler için kütlenin korunumu RHVT’ne göre Eşitlik 1' deki yazilabilir.

$\sum \dot{m}_{g}=\sum \dot{m}_{c}$

$m_{g}:$ RHVT giriş akışkanın hacimsel debisi, $1 / \mathrm{s}$

$m_{c}:$ RHVT çıkış akışkanın hacimsel debisi, 1/s

Eşitlik 1 RHVT için Eşitlik 2 şeklinde yazılabilir.

$m_{c}=m_{a}+m_{b}$

$m_{a}:$ RHVT çıkan sıcak akışkanın hacimsel debisi, 1/s

$\dot{m}_{b}:$ RHVT çıkan soğuk akışkanın hacimsel debisi, $1 / \mathrm{s}$.

Girişteki akışkan sıcaklığı $\left(T_{\text {gir }}\right)$ ile soğuk uçtaki akışkan sıcaklık $\left(T_{\text {sog }}\right)$ farkı, soğuk akışkan sıcaklık farkı $\Delta \mathrm{T}_{\text {sog }}$ olarak tanımlanmış ve Eşitlik 3 ile verilmiştir.

$\Delta T_{\text {sog }}=T_{\text {sog }}-T_{\text {gir }}$

Girişteki akışkan sıcaklığı $\left(\mathrm{T}_{\text {gir }}\right)$ ile sıcak uçtaki akışkan sıcaklık $\left(\mathrm{T}_{\text {sck }}\right)$ farkı, sıcak akışkan sıcaklık farkı $\Delta \mathrm{T}_{\text {sck }}$ olarak verilmiş ve Eşitlik 4 ile verilmiştir.

$\Delta T_{s c k}=T_{s c k}-T_{g i r}$

RHVT performansı, çıkan sıcak akış sıcaklığı ile çıkan soğuk akışın sıcaklığı arasındaki fark olan cinsinden Eşitlik 5 ile verilmiştir [3, 14, 16].

$\Delta T=T_{\text {sck }}-T_{\text {sog }}$

Şekil 4 oluşturulan deneysel sistemde kullanılan polyamid, alüminyumun ve pirinç malzemeden nozulun $(\mathrm{N})$, giriş basıncı $\left(\mathrm{P}_{\text {gir }}\right) 200 \mathrm{kPa}$ bar dan $50 \mathrm{kPar}$ aralıklarla $600 \mathrm{kPa}$ basınç değerine çıkan soğuk akışkan çıkış ucunda ölçülen sıcaklıklar $\left(\mathrm{Ts}_{\mathrm{og}}\right)$ şekil 6 de verilmiştir. 


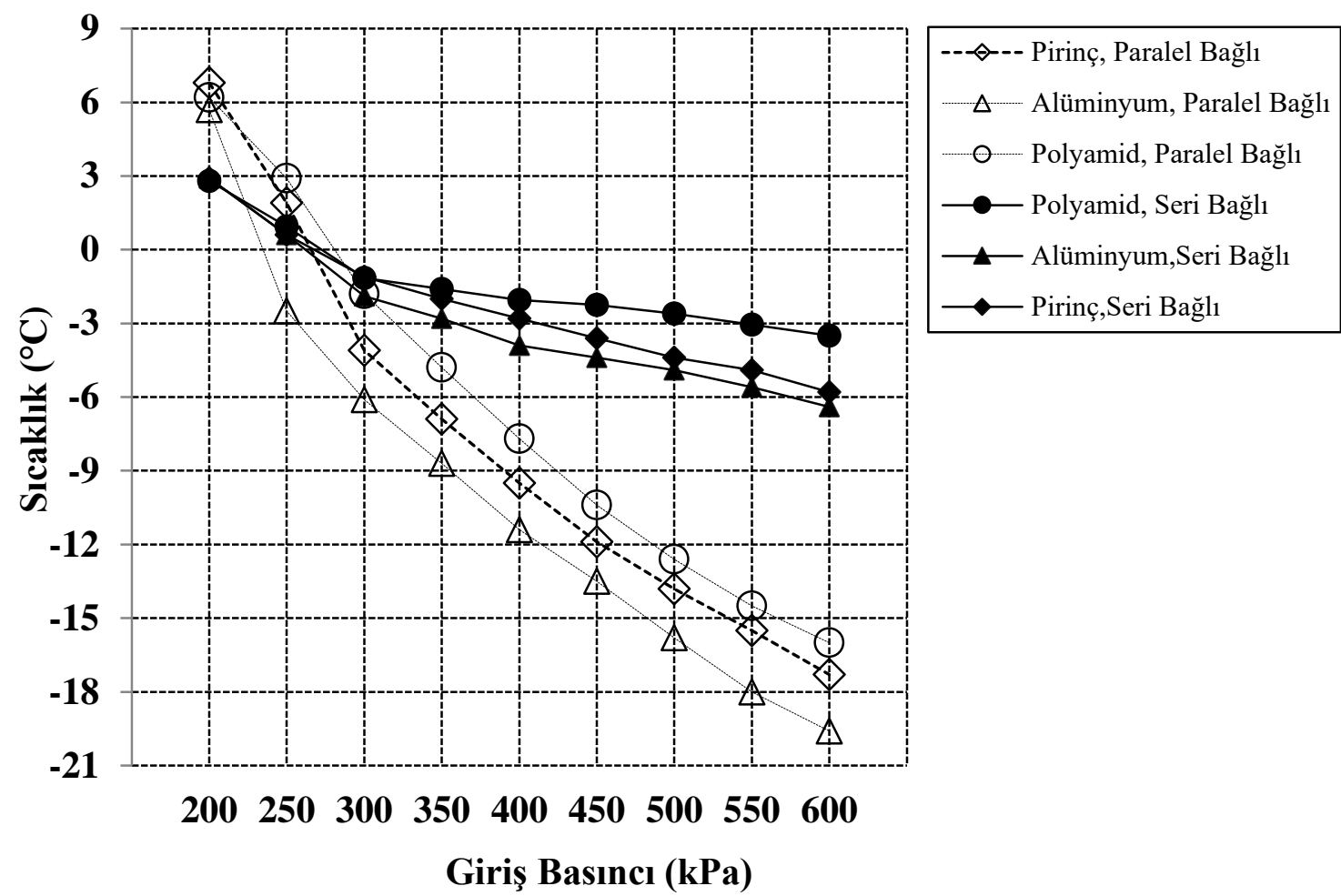

Şekil 6. Giriş Basıncı ile $T_{\text {sog }}$ değişim grafiği

Şekil 6 incelendiğinde, Polyamid Plastik, Alüminyumun ve Pirinç malzemeden üretilmiş 6 nozul (N) için en yüksek $T_{\text {soğ }}$ incelendiğinde; Seri bağlı deneysel de en düşük $T_{\text {sog }}$ Alüminyumun malzemeden üretilmiş $\mathrm{N}=6$ ve $\mathrm{P}_{\text {gir }}=600 \mathrm{kPa}$ değerinde $-6.4{ }^{\circ} \mathrm{C}$ olduğu, Paralel bağl1 deneysel sistem de en düşük $\mathrm{T}_{\text {sog }}$ değeri ise Alüminyumun malzemeden üretilmiş $\mathrm{N}=6$ ve $\mathrm{P}_{\text {gir }}=600 \mathrm{kPa}$ değerinde $-19.6{ }^{\circ} \mathrm{C}$ olduğu görülmektedir. Seri bağlı deneysel de en yüksek $\mathrm{T}_{\text {sog }}$ Polyamid Plastik malzemeden üretilmiş $\mathrm{N}=6$ ve $\mathrm{P}_{\text {gir }}=200 \mathrm{kPa}$ değerinde $2.8{ }^{\circ} \mathrm{C}$ olduğu, Paralel bağlı deneysel sistem de en yüsek $\mathrm{T}_{\text {sog }}$ değeri ise Pirinç malzemeden üretilmiş $\mathrm{N}=6$ ve $\mathrm{P}_{\text {gir }}=200 \mathrm{kPa}$ değerinde $6.8{ }^{\circ} \mathrm{C}$ olduğu deneysel olarak tespit edilmiştir (Şekil 6). Deneysel sistemde kullanılan polyamid, alüminyumun ve pirinç malzemeden nozulun $(\mathrm{N})$, giriş basıncı (Pgir) $200 \mathrm{kPa}$ bar dan $50 \mathrm{kPar}$ aralıklarla $600 \mathrm{kPa}$ basınç değerine çıkan sıcak akışkan çıkış ucunda ölçülen sıcaklıklar $\left(\mathrm{T}_{\text {sck }}\right)$ şekil 7 de verilmiştir. 


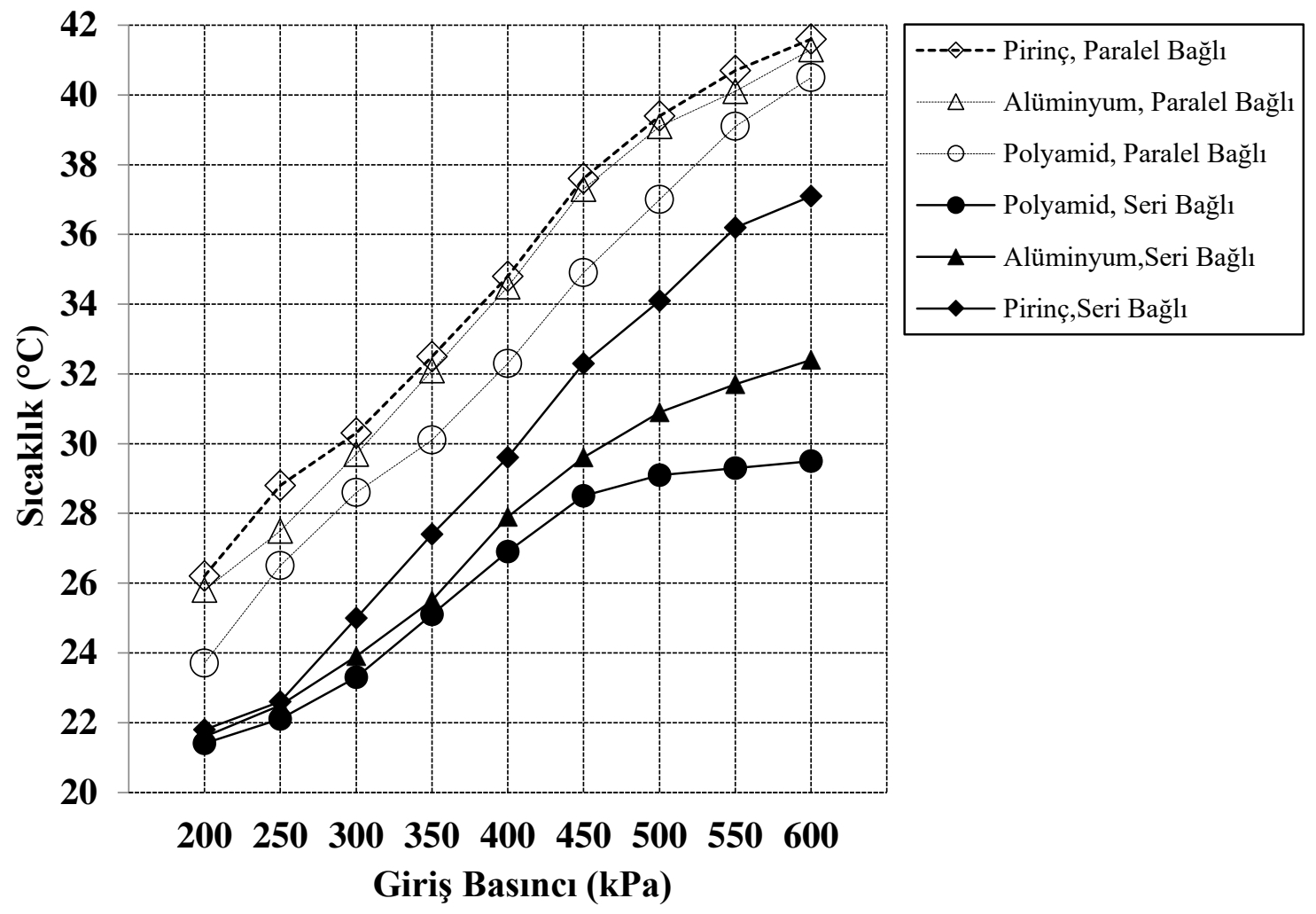

Şekil 7. Giriş Basıncı ile $T_{\text {sck }}$ değişim grafiği

Şekil 7 incelendiğinde, Polyamid Plastik, Alüminyumun ve Pirinç malzemeden üretilmiş 6 nozul (N) için $\mathrm{T}_{\text {sck }}$ incelendiğinde; Seri bağlı deneysel de en yüksek $\mathrm{T}_{\text {sck }}$ Pirinç malzemeden üretilmiş $\mathrm{N}=6$ ve $\mathrm{P}_{\text {gir }}=600$ $\mathrm{kPa}$ değerinde $37.1^{\circ} \mathrm{C}$ olduğu, Paralel bağlı deneysel sistem de en yüksek $\mathrm{T}_{\text {sck }}$ değeri ise Pirinç malzemeden üretilmiş $\mathrm{N}=6$ ve $\mathrm{P}_{\text {gir }}=600 \mathrm{kPa}$ değerinde $41.6{ }^{\circ} \mathrm{C}$ olduğu görülmektedir. Seri bağl1 deneysel de en düşük $\mathrm{T}_{\text {sck }}$ Polyamid Plastik malzemeden üretilmiş $\mathrm{N}=6$ ve $\mathrm{P}_{\text {gir }}=200 \mathrm{kPa}$ değerinde $21.4^{\circ} \mathrm{C}$ olduğu, Paralel bağ 1 deneysel sistem de en düşük $T_{\text {sck }}$ değeri ise Polyamid Plastik malzemeden üretilmiş $\mathrm{N}=6$ ve $\mathrm{P}_{\text {gir }}=200 \mathrm{kPa}$ değerinde $23.7{ }^{\circ} \mathrm{C}$ olduğu deneysel olarak tespit edilmiştir (Şekil 7).

Deneysel sistemde kullanılan polyamid, alüminyumun ve pirinç malzemeden nozulun $(\mathrm{N})$, giriş basıncı (Pgir) $200 \mathrm{kPa}$ bar dan $50 \mathrm{kPar}$ aralıklarla $600 \mathrm{kPa}$ basınç değerine kadar deneysel sistemin performans değeri olarak da adlandırılan sıcak akışkan çıkış ucunda ölçülen $T_{\text {sck }}$ ile soğuk akışkan çıkış ucunda ölçülen $\mathrm{T}_{\mathrm{sog}}$ arasındaki fark olan, $\Delta \mathrm{T}$ değerleri Şekil 8 de verilmiştir.Şekil 8 incelendiğinde, Polyamid Plastik, Alüminyumun ve Pirinç malzemeden üretilmiş 6 nozul $(\mathrm{N})$ için $\Delta \mathrm{T}$ incelendiğinde; Seri bağlı deneysel de en yüksek $\Delta \mathrm{T}$ Pirinç malzemeden üretilmiş $\mathrm{N}=6$ ve $\mathrm{P}_{\text {gir }}=600 \mathrm{kPa}$ değerinde $42.9^{\circ} \mathrm{C}$ olduğu, Paralel bağl1 deneysel sistem de en yüksek $\Delta \mathrm{T}$ değeri ise Alüminyumun malzemeden üretilmiş $\mathrm{N}=6$ ve $\mathrm{P}_{\text {gir }}=600 \mathrm{kPa}$ değerinde $60.9^{\circ} \mathrm{C}$ olduğu görülmektedir. Seri bağlı deneysel de en düşük $\Delta \mathrm{T}$ Polyamid Plastik malzemeden üretilmiş $\mathrm{N}=6$ ve $\mathrm{P}_{\text {gir }}=200 \mathrm{kPa}$ değerinde $18.6^{\circ} \mathrm{C}$ olduğu, Paralel bağlı deneysel sistem de en düşük $\Delta \mathrm{T}$ değeri ise Polyamid Plastik malzemeden üretilmiş $\mathrm{N}=6$ ve $\mathrm{P}_{\text {gir }}=200 \mathrm{kPa}$ değerinde $17.5^{\circ} \mathrm{C}$ ölçülmüştür (Şekil 8). 


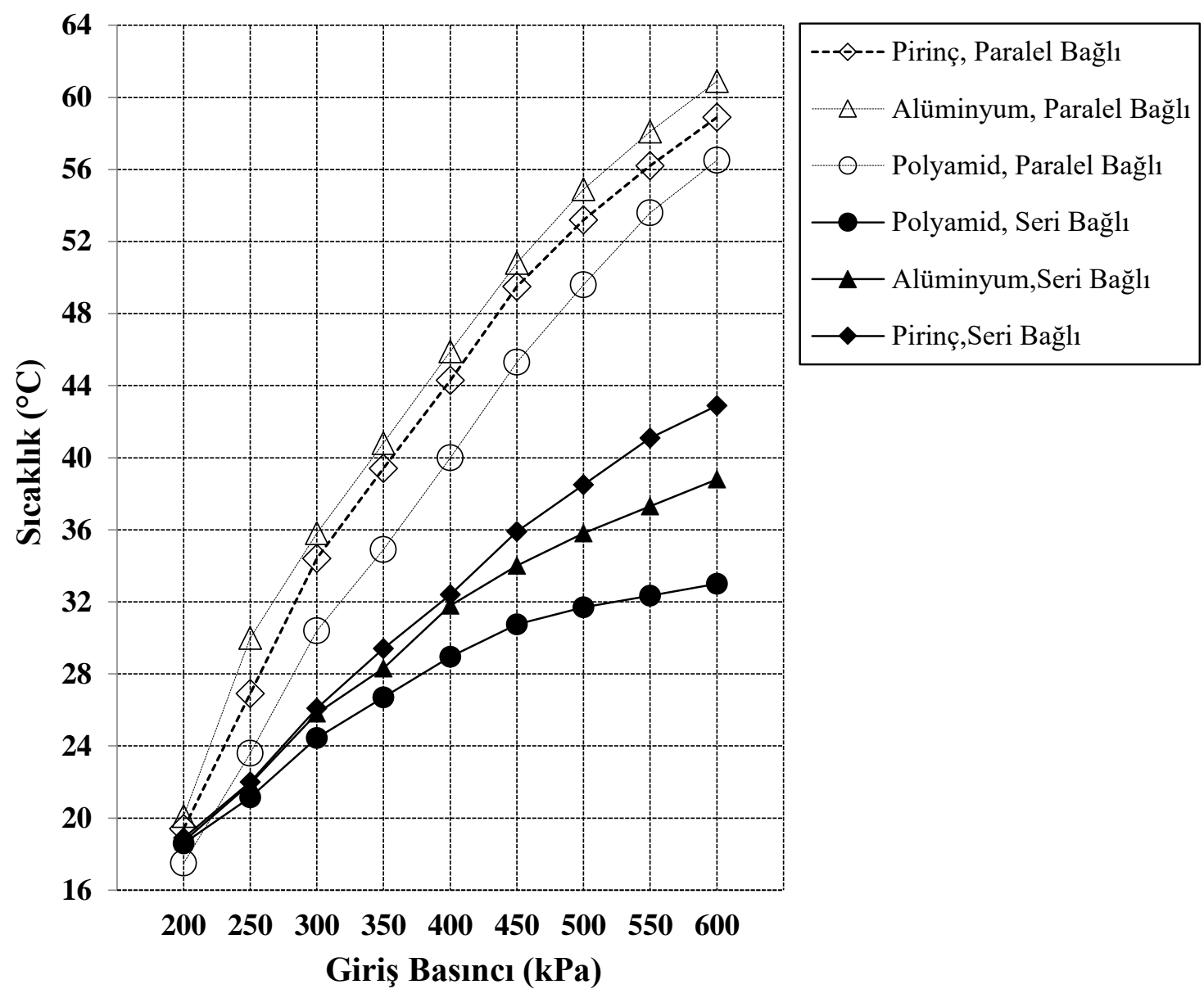

Şekil 8. Giriş Basıncı ile $\Delta T$ değişim grafiği

\section{SONUÇ ve ÖNERILER}

Bu çalışmada, tasarımı yapılan deney sisteminde nozul sayısı 6 olan Polyamid Plastik, Alüminyumun ve Çelik malzemeden üretilmiş, basınçlı akışkan olarak hava kullanılan, $200 \mathrm{kPa}$ ' dan başlayarak $600 \mathrm{kPa}$ basınç değerine kadar $50 \mathrm{kPa}$ aralıklarla soğutma ve 1sıtma performansı incelenmiştir. Bu çalışma bağlantı şekline göre oluşturulan deneysel sistemler giriş basıncı ve nozul malzemesine arasındaki ilişki deneysel olarak incelenmiştir. Deneysel sonuçlar değerlendirildiğinde oluşturulan deneysel giren havanın giriş basıncı arttırıldıkça, soğuk çıkıştaki akışkan sıcaklığı düşmektedir. Paralel ile Seri bağlı sistemler aralarında mukayese edildiğinde, en düşük soğuk akışkan sıcaklığ $\mathrm{P}_{\text {gir }}=600 \mathrm{kPa}$ değerinde Alüminyumun malzemeden üretilmiş nozulda $-19.6{ }^{\circ} \mathrm{C}$ Paralel bağl1 deneysel sistemde olduğu tespit edilmiştir (Şekil 6). Deneysel sonuçlar değerlendirildiğinde oluşturulan deneysel giren havanın giriş basıncı arttırıldıkça, sıcak çıkıştaki akışkan sıcaklığı artmaktadır. Paralel ile Seri bağlı sistemler aralarında mukayese edildiğinde, en yüksek sıcak akışkan sıcaklığ $\mathrm{P}_{\text {gir }}=600 \mathrm{kPa}$ değerinde Pirinç malzemeden üretilmiş nozulda $41.6{ }^{\circ} \mathrm{C}$ Paralel bağlı deneysel sistemde olduğu tespit edilmiştir (Şekil 7). Deneysel sonuçlar değerlendirildiğinde, havanın giriş basıncı arttırıldıkça deneysel sistemin performans değeri olarak da adlandırılan sıcak akışkan çıkış ucunda ölçülen $T_{\text {sck }}$ ile soğuk akışkan çıkış ucunda ölçülen $T_{\text {soğ }}$ arasındaki fark olan, $\Delta T$ artmaktadır. Paralel ile Seri bağlı sistemler aralarında mukayese edildiğinde, en yüksek $\Delta \mathrm{T}, \mathrm{P}_{\text {gir }}=600 \mathrm{kPa}$ değerinde Alüminyumun malzemeden üretilmiş nozulda $60.9{ }^{\circ} \mathrm{C}$ Paralel bağlı deneysel sistemde olduğu tespit edilmiştir (Şekil 8). Şekil 6, 7 ve 8 incelendiğinde giriş basınc1 $500 \mathrm{kPa}$ kadar $\mathrm{T}_{\text {soğ }}$, $\mathrm{T}_{\text {sck }}$ ve $\Delta \mathrm{T}$ değişimlerinin hızlı olduğu ancak $500 \mathrm{kPa}$ sonra $\mathrm{T}_{\text {sgk }}, \mathrm{T}_{\text {sck }}$ ve $\Delta \mathrm{T}$ değişimlerinin azaldığı görülmektedir.Giriş basıncı artıkça soğutma - 1sıtma performansı artacağı önerilmektedir. Yapılan bu çalışma farklı nozul malzemeleri, sayısı ve geometrik yapı ile yapılacak olan diğer çalışmalar için temel alınarak uygulanabileceği görüşüne sahip olunmuştur. 


\section{KAYNAKLAR}

[1] H. Usta, V. Kırmacı, K. Dincer, Vorteks Tüpünde Akışkan Olarak Kullanılan Hava, Oksijen ve Karbondioksitin Soğutma-Isıtma Sicaklık Performanslarının Deneysel Olarak İncelenmesi. Teknoloji, 8: 4 (2005) 311-319.

[2] İ. Cebeci, V. Kirmac1, U. Topcuoglu, The Effects of Orifice Nozzle Number and Nozzle Made of Polyamide Plastic and Aluminum with Different Inlet Pressures on Heating and Cooling Performance of Counter Flow Ranque-Hilsch Vortex Tubes: An Experimental Investigation. International Journal of Refrigeration, 72 (2016) 140-146.

[3] V. Kırmac1, O. Uluer, K. Dincer, Exerg Analysis and Performance of a Counter flow Vortex Tube: An Experimental Investigation with Various Nozzle Numbers at Different Inlet Pressures of Air, Oxygen, Nitrogen And Argon. Journal of Heat Transfer-Transactions of The Asme, 12 (2010) 121701-121701.

[4] A. Pinar, O. Uluer, V. Kirmac1, Optımızation Of Counter Flow Ranque-Hilsch Vortex Tube Performance Using Taguch1 Method. International Journal of Refrigeration, 32: 6 (2009) 1487-1494.

[5] V. Kırmacı, İ. Cebeci, M. Y. Balalı, Altı Nozullu Karşıt Akışlı Vorteks Tüpünün Performansının Deneysel Olarak İncelenmesi. Bartın Üniversitesi Mühendislik ve Teknoloji Bilimleri Dergisi, 1: 1 (2013) 77-95.

[6] İ. Cebeci, M. Y. Balalı, V. Kırmacı, Karşıt Akışlı Ranque-Hilsch Vorteks Tüpünde Hava ve Oksijen Akışkanlarının Farklı Nozul Numaralarında Enerji-Ekserji Analizlerinin Deneysel Olarak İncelenmesi. Bartın Üniversitesi Mühendislik ve Teknoloji Bilimleri Dergisi, 2: 2 (2014) 56-77.

[7] W. Fröhlıngsdorf, H. Unger, Numerical Investigations of Compressible Flow and The Eneryg Seperation in The Ranque-Hilsch Vortex Tube. International Journal of Heat and Mass Transfer, 42 (1999) 415-422.

[8] V. Kırmacı, Akışkan Olarak Hava Oksijen Karbondioksit Azot Argon ve Karışım Gazı Kullanılan Vorteks Tüpünde Soğutma-Isıtma Sicaklık Performanslarının Deneysel Olarak İncelenmesi. Fırat Üniversitesi Fen ve Mühendislik Bilimleri Dergisi, 20: 2 (2008) 345-354.

[9] V. Kırmacı, H. Usta, T. Tenlik, Vorteks Tüpünde Akışkan Olarak Hava Oksijen Karbondioksit Azot Ve Argon Kullanılarak Isıtma-Soğutma Sıcaklık Performanslarının Deneysel Olarak Karşılaştııılması. Sakarya Ünv. Fen Bil. Enst. Dergisi, 10: 2 (2006) 39-44.

[10] H. Usta, K. Dincer, V. Kırmacı, Vorteks Tüpünde Akışkan Olarak Kullanılan Hava İle Oksijenin Soğutma Sıcaklık Performanslarının Deneysel İncelenmesi. Teknoloji, 7: 3 (2004) 415-425.

[11] H. Usta, V. Kırmacı, K. Dincer, Vorteks Tüpünde Akışkan Olarak Kullanılan Hava İle Azot Gazının Soğutma Sıcaklık Performanslarının Deneysel İncelenmesi. Balıkesir Ünv. Fen Bil. Enst. Dergisi, 6: 2 (2004) 67-76.

[12] V. Kırmacı, Altı Nozullu Vorteks Tüpünün Soğutma-Isıtma Sicaklık Performanslarının Deneysel Olarak İncelenmesi. Politeknik Dergisi, 10: 4 (2007) 219-227.

[13] V. Kirmac1, O. Uluer, The Effects of Orifice Nozzle Number on Heating and Cooling Performance of Vortex Tubes: An Experimental Study. Instrumentation Science and Technology, 36: 5 (2008) 493502.

[14] V. Kirmac1, Exergy Analysis And Performance Of A Ranque-Hilsch Counter Flow Vortex Tube Having Various Nozzle Numbers At Different Inlet Pressures Of Oxygen And Air. International Journal of Refrigeration, 32: 7 (2009) 1626-1633.

[15] B. Markal, Ranque-Hılsch Vorteks Tüpünde Enerji Ayrışmasının Deneysel ve Termodinamik İncelenmesi. Yüksek Lisans Tezi, KTÜ Fen Bilimleri Enstitüsü, 2010. 
[16] İ. Cebeci, Karşıt Akışlı Ranque-Hilsch Vorteks Tüpünde Hava Ve Oksijen Akışkanlarının Farklı Nozul Numaralarında Enerji-Ekserji Analizlerinin Deneysel Olarak İncelenmesi. Yüksek Lisans Tezi, Bartın Üniversitesi Fen Bilimleri Enstitüsü, 2013.

[17] S. Yüksel, CNC tornalamada vorteks tüplü soğutma sistemi performansının incelenmesi. Yüksek Lisans Tezi, Marmara Üniversitesi Fen Bilimleri Enstitüsü, 2014. 